\title{
Meiotic competence in vitro of pig oocytes isolated from early antral follicles*
}

\author{
J. Motlik, Nicole Crozet and J. Fulka \\ Czechoslovak Academy of Sciences, Institute of Animal Physiology and Genetics, Department of \\ Genetics, 27721 Libechov, Czechoslovakia
}

\begin{abstract}
Summary. Pig oocytes were isolated from early antral follicles of different sizes and their abilities to resume and complete meiotic maturation in vitro were compared. After $24 \mathrm{~h}$ of culture, more than $80 \%$ of the oocytes from follicles $0.3-0.7 \mathrm{~mm}$ in diameter remained at the germinal vesicle stage, while $66,94.3$ and $100 \%$ oocytes from follicles $0 \cdot 8-1 \cdot 6,1 \cdot 7-2 \cdot 2$ and $3-5 \mathrm{~mm}$ in diameter, respectively, completed germinal vesicle breakdown. After $48 \mathrm{~h}$ of culture, $35 \%$ of the oocytes in the smallest follicle class progressed to prometaphase and only $4 \%$ to metaphase I. Of the oocytes from follicles $0.8-1.6 \mathrm{~mm}$ in diameter, $23 \%$ reached metaphase I and $17.3 \%$ metaphase II. About 50 and $76 \%$ of the oocytes from follicles $1.8-2 \cdot 2 \mathrm{~mm}$ and $3-5 \mathrm{~mm}$ in diameter, respectively, extruded the first polar body.

The ability to resume meiosis (i.e. to undergo germinal vesicle breakdown) is reached by porcine oocytes when they approach their full size in antral follicles $>0.8$ $\mathrm{mm}$ in diameter and before they are capable of completing it (i.e. reaching metaphase II). The ability to complete meiotic maturation acquired in antral follicles of about 2 $\mathrm{mm}$ in diameter coincided with a significant decrease in the nucleolar transcriptional activity of the oocytes.
\end{abstract}

\section{Introduction}

When mammalian oocytes are released from preovulatory follicles, meiosis spontaneously resumes. However, conflicting results concerning the ability of pig oocytes from small antral follicles to resume maturation in vitro have been reported. While McGaughey, Montgomery \& Richter (1979) claimed that about $80 \%$ of oocytes from follicles of 1-2 mm in diameter are capable of undergoing germinal vesicle breakdown, Tsafriri \& Channing (1975) and Anderson \& Hillensjö (1982) indicated that the incidence of maturation of oocytes from the same class is only $15-25 \%$. Crozet, Motlik \& Szöllösi (1981) showed that important morphological and functional changes occur in vivo in the nucleolus of pig oocytes during the early stages of antrum formation.

In the present study, oocytes were isolated from different classes of early antral follicles and their abilities to resume and complete meiotic maturation were compared. Oocyte competence has been related to oocyte size as well as to nucleolar structure and function.

\section{Materials and Methods}

Cyclic gilts of miniature pig crosses of the Minnesota and Göttingen strains were slaughtered on Days $2-4$ and $8-10$ of the cycle. The excised ovaries were immediately placed in warm phosphateFrance.

* Reprint requests to Dr N. Crozet, Station Centrale de Physiologie Animale, INRA, 78350 Jouy-en-Josas, 


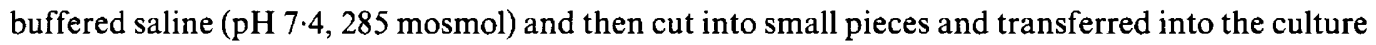
medium (see below) which was continuously bubbled with $5 \% \mathrm{CO}_{2}$ in air. Antral follicles were isolated under a dissection microscope, measured with a micrometer $(\times 25$ magnification $)$ and divided into four classes according to diameter: Class A : $0.3-0.7 \mathrm{~mm}$; Class B: $0.8-1.6 \mathrm{~mm}$; Class C: $1 \cdot 7-2 \cdot 2 \mathrm{~mm}$; Class D: $3-5 \mathrm{~mm}$.

The oocytes were isolated by rupture of the follicular wall, and only those surrounded by cumulus cells were cultured in $0.1 \mathrm{ml}$ culture medium as drops under paraffin oil at $38^{\circ} \mathrm{C}$ under $5 \%$ $\mathrm{CO}_{2}$ in air. The culture medium contained $72 \mathrm{ml}$ isotonic TC 199 medium (Usol, Prague); $18 \mathrm{ml}$ $1.45 \% \mathrm{NaHCO}_{3}+0.002 \%$ phenol red $; 10 \mathrm{ml} \mathrm{5.5 \% (w/v)} \mathrm{glucose} \mathrm{solution;} 0.004 \mathrm{~g}$ sodium pyruvate; $10 \mathrm{mg}$ freeze-dried calf serum growth protein (Usol) $/ \mathrm{ml} ; 50$ i.u. penicillin and $5 \mathrm{mg}$ streptomycin $/ \mathrm{ml}$. The supplements were dissolved in 3 times distilled water. After 24 or $48 \mathrm{~h}$ of culture, the cumulus cells were removed mechanically and the oocytes were mounted on slides, fixed in acetic alcohol $(1: 3 \mathrm{v} / \mathrm{v})$ for $24 \mathrm{~h}$, stained with $1 \%$ orcein and examined by phase-contrast microscopy. The diameter of at least 40 oocytes from each follicular class was measured with an ocular micrometer ( $\times 200$ magnification) immediately after isolation and removal of the cumulus cells. These oocytes were fixed and stained (see above) and served as control for germinal vesicle configuration before culture. Mean diameter and standard error of the mean were evaluated for each follicular class. Differences between the classes were tested by one-way analysis of variance.

For electron microscopy, oocytes were washed immediately after culture in cold $\left(+4^{\circ} \mathrm{C}\right) \mathrm{PBS}$, fixed for $60 \mathrm{~min}$ in $2.5 \%(\mathrm{v} / \mathrm{v})$ glutaraldehyde and $0.75 \%$ paraformaldehyde in $0.075 \mathrm{M}$-cacodylate buffer containing $0 \cdot 1-1 \cdot 5 \%$ potassium ferricyanide. They were then post-fixed for $60 \mathrm{~min}$ in $2 \%$ osmium tetroxide, washed in distilled water and stained overnight in a $0.5 \%$ aqueous uranyl acetate solution at $4^{\circ} \mathrm{C}$. The oocytes were embedded in Durcupan (Fluka). Thin sections were stained with uranyl acetate for $30 \mathrm{~min}$ and with lead citrate for $10 \mathrm{~min}$.

\section{Results}

\section{Morphology}

Nucleoli with small and large vacuoles were observed in the germinal vesicle of all Class A oocytes (Pl. 1, Figs $1 \& 2$ ). More than $50 \%$ of Class B oocytes showed the formation of a compact nucleolus, while large nucleolar vacuoles still prevailed in the other oocytes. About $60 \%$ of the oocytes isolated from Class $\mathrm{C}$ follicles had a compact nucleolus (P1. 1, Fig. 3), sometimes

\section{PLATE 1}

Figs 1-4. Pig oocytes before culture mounted on slides, fixed in acetic alcohol $(1: 3 \mathrm{v} / \mathrm{v})$ and stained with $1 \%$ orcein (Loba-Chemic, Vienna) were photographed with phase-contrast microscopy. $\times 1600$.

Fig. 1. Two nucleoli of an oocyte from a follicle $0.4 \mathrm{~mm}$ in diameter. The arrow indicates the position of the smaller nucleolus (see inset). Numerous nucleolar vacuoles are visible. Heterochromatic knobs in the nucleoplasm are indicated by arrowheads.

Fig. 2. Nucleolus with small and large vacuoles of an oocyte from a follicle $0.6 \mathrm{~mm}$ in diameter.

Fig. 3. Oocyte isolated from a follicle $1.6 \mathrm{~mm}$ in diameter; fine filamentous bivalents surround the nucleolar area $(\mathrm{N})$. The nucleolus is out of focus.

Fig. 4. Germinal vesicle of an oocyte from a follicle $2.2 \mathrm{~mm}$ in diameter with a compact nucleolus. Well-stained condensed chromatin is localized around the nucleolus. No chromatin condensation is apparent in the finely stained granulated nucleoplasm.

Fig. 5. Electron micrograph of a vacuolated nucleolus composed of fibrillo-granular elements (fg) of an oocyte from a follicle $0 \cdot 3-0 \cdot 7 \mathrm{~mm}$ in diameter cultured for $24 \mathrm{~h} . \times 24500$. 
PLATE 1
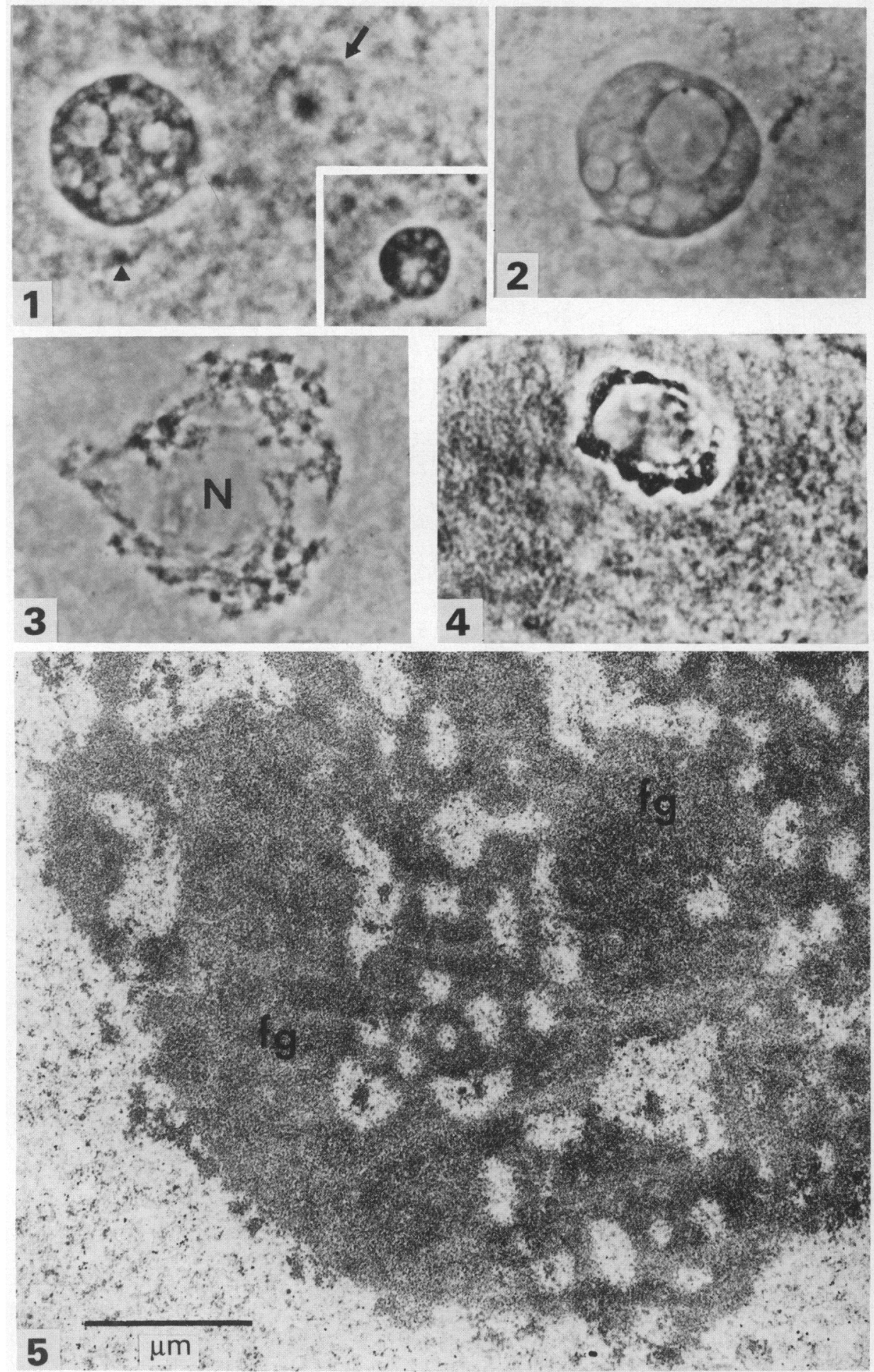
PLATE 2
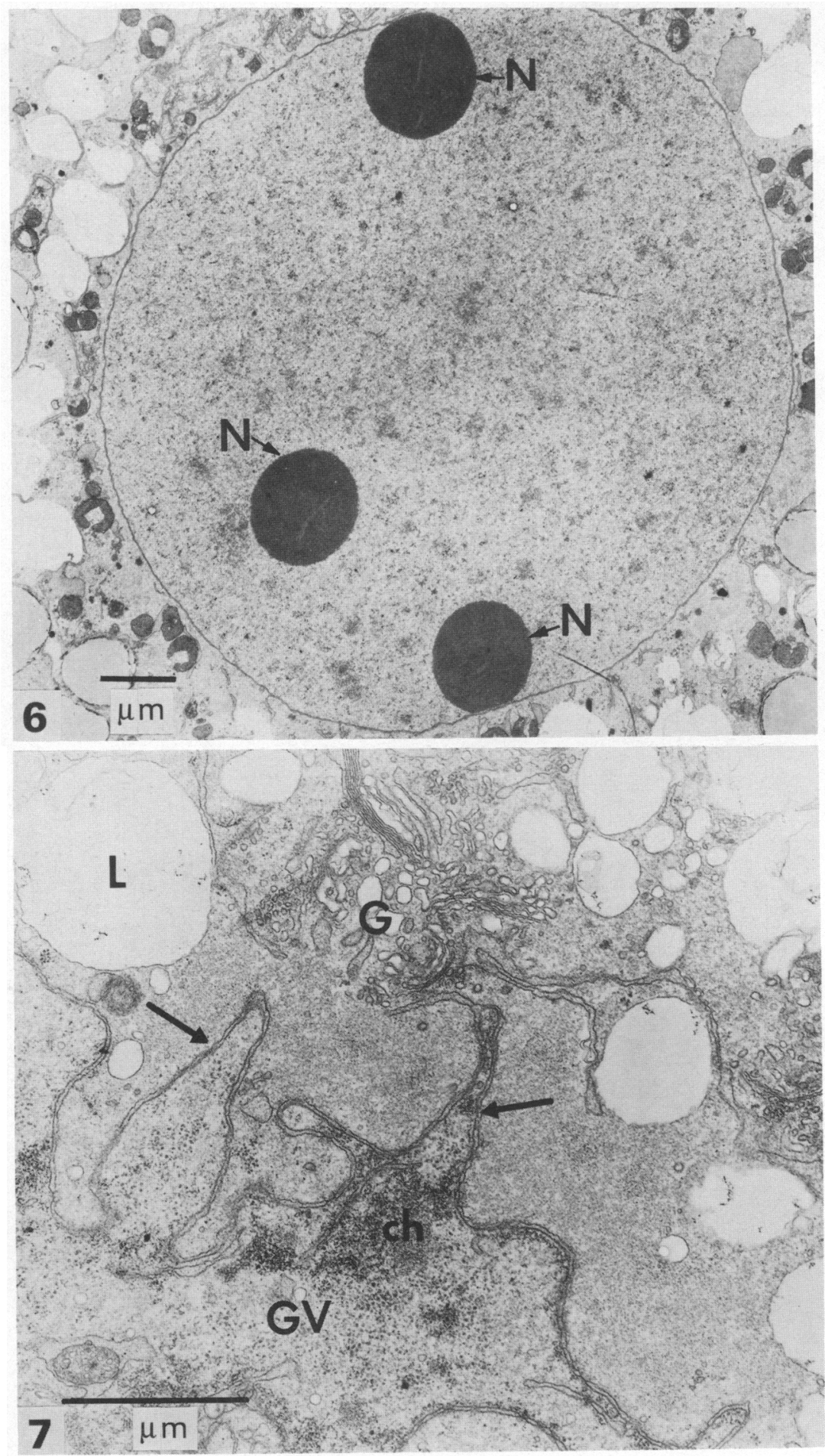


\section{PLATE 3}
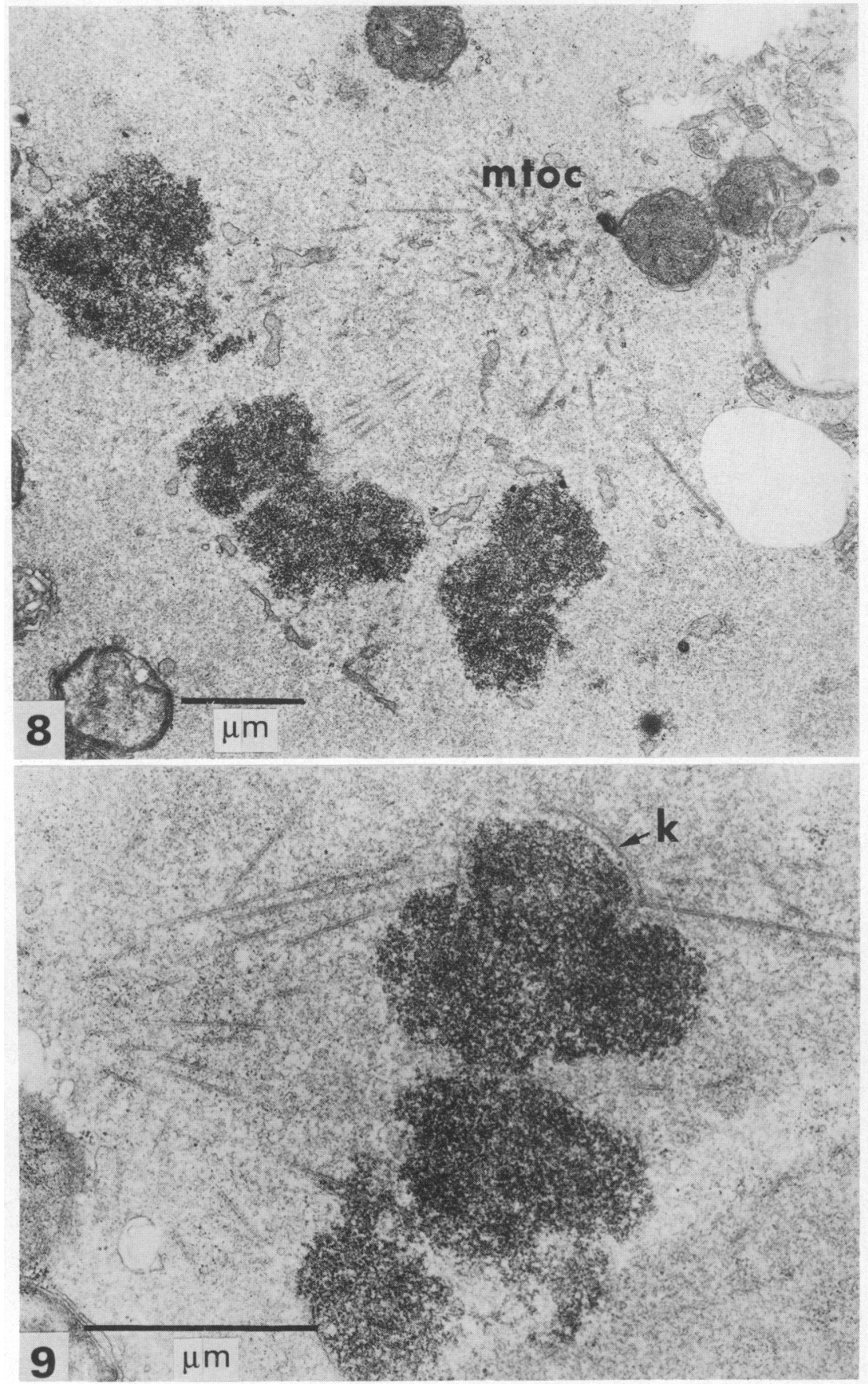

Fig. 8. Metaphase I of an oocyte from a follicle $0.8-1.6 \mathrm{~mm}$ in diameter cultured for $48 \mathrm{~h}$; mtoc, microtubule organizing centre. $\times 16000$.

Fig. 9. Metaphase II spindle of an oocyte from a $1 \cdot 8-2.2 \mathrm{~mm}$ follicle cultured for $48 \mathrm{~h} ; \mathbf{k}$, kinetochore. $\times 30000$. 
surrounded by filamentous chromatin. However, condensed heterochromatin was present around the compact nucleolus of all Class D oocytes isolated from the ovaries at Days 8-10 of the cycle ( $\mathrm{Pl}$. 1, Fig. 4).

The mean \pm s.e.m. diameter (excluding the zona pellucida) of oocytes from the smallest follicles (Class A) was about $100 \mu \mathrm{m}(101.85 \pm 3.68 \mu \mathrm{m})$. Further oocyte growth was observed in Classes B and $C$ in which oocyte diameter reached $109.59 \pm 2.65$ and $115.09 \pm 2.17 \mu \mathrm{m}$ respectively. Mean oocyte diameter in Class $\mathrm{D}$ was $119.87 \pm 3.76 \mu \mathrm{m}$. The differences between the 4 classes were significant $(P<0.01)$. These data demonstrate that the pig oocytes from early antral follicles of up to $2 \cdot 2 \mathrm{~mm}$ diameter had not completed growth.

\section{Culture for $24 \mathrm{~h}$}

Oocytes from Class A follicles showed a very limited ability to initiate nuclear maturation after $24 \mathrm{~h}$ of culture in vitro (Table 1); more than $80 \%$ remained at the germinal vesicle stage. Under the electron microscope, the nucleoli of 6 oocytes analysed showed a vacuolated and fibrillo-granular structure (Pl. 1, Fig. 5) like that of the oocytes before culture (not shown). Only $12 \%$ of these Class A oocytes continued to prometaphase. In contrast $66,94.3$ and $100 \%$ of oocytes from follicles from Classes B, C, and D, respectively, progressed beyond the germinal vesicle stage.

Table 1. Maturation of pig oocytes isolated from antral follicles after culture

\begin{tabular}{|c|c|c|c|c|c|c|c|c|}
\hline \multirow[b]{2}{*}{$\begin{array}{l}\text { Culture } \\
\text { period }\end{array}$} & \multirow[b]{2}{*}{$\begin{array}{l}\text { Follicular } \\
\text { diam. } \\
(\mathrm{mm})\end{array}$} & \multirow[b]{2}{*}{$\begin{array}{l}\text { Total } \\
\text { no. of } \\
\text { oocytes }\end{array}$} & \multirow[b]{2}{*}{$\begin{array}{l}\text { No. of } \\
\text { exps }\end{array}$} & \multicolumn{5}{|c|}{ Percentage of oocytes in: } \\
\hline & & & & $\begin{array}{l}\text { Germinal } \\
\text { vesicle }\end{array}$ & $\begin{array}{c}\text { Pro- } \\
\text { metaphase }\end{array}$ & Metaphase I & Metaphase II & $\begin{array}{l}\text { Clumps of } \\
\text { condensed } \\
\text { chromatin* }\end{array}$ \\
\hline \multirow[t]{4}{*}{$24 \mathrm{~h}$} & $\begin{array}{c}0.3-0.7 \\
(\text { Class A) }\end{array}$ & 177 & 5 & $85 \pm 1.5$ & $12 \pm 1 \cdot 33$ & 0 & 0 & $3 \pm 0.6$ \\
\hline & $\begin{array}{c}0.8-1.6 \\
\text { (Class B) }\end{array}$ & 146 & 5 & $28 \pm 1 \cdot 2$ & $53 \pm 5$ & $13 \pm 1.9$ & 0 & $6 \pm 2 \cdot 1$ \\
\hline & $\begin{array}{c}1 \cdot 7-2 \cdot 2 \\
(\text { Class C) }\end{array}$ & 140 & 5 & $6 \pm 3.9$ & $46 \pm 0 \cdot 4$ & $49 \pm 4 \cdot 3$ & 0 & 0 \\
\hline & $\begin{array}{c}3-5 \\
\text { (Class D) }\end{array}$ & 138 & 5 & 0 & $43 \pm 1 \cdot 3$ & $48 \pm 0.6$ & $8 \pm 4 \cdot 2$ & 0 \\
\hline \multirow[t]{4}{*}{$48 \mathrm{~h}$} & $\begin{array}{c}0.3-0.7 \\
\text { (Class A) }\end{array}$ & 155 & 5 & $41 \pm 12 \cdot 1$ & $35 \pm 11 \cdot 4$ & $4 \pm 0.4$ & 0 & $20 \pm 2 \cdot 5$ \\
\hline & $\begin{array}{c}0.8-1.6 \\
\text { (Class B) }\end{array}$ & 121 & 5 & $17 \pm 1 \cdot 2$ & $18 \pm 1 \cdot 1$ & $23 \pm 2 \cdot 5$ & $17 \pm 0.3$ & $25 \pm 2 \cdot 1$ \\
\hline & $\begin{array}{c}1 \cdot 7-2 \cdot 2 \\
(\text { Class C) }\end{array}$ & 122 & 5 & 3 & 0 & $31 \pm 0.2$ & $49 \pm 4 \cdot 2$ & $17 \pm 3 \cdot 3$ \\
\hline & $\begin{array}{c}3-5 \\
\text { (Class D) }\end{array}$ & 116 & 5 & 0 & 0 & $24 \pm 1 \cdot 6$ & $76 \pm 2 \cdot 5$ & 0 \\
\hline
\end{tabular}

Values are mean \pm s.e.m.

* Oocytes with pycnotic chromatin indicating no further competence to mature.

\section{PLATE 2}

Fig. 6. Germinal vesicle of an oocyte from a $0.5-0.7 \mathrm{~mm}$ follicle cultured for $48 \mathrm{~h} ; 3$ small compact nucleoli $(\mathrm{N})$ are present in the round nucleus. $\times 10000$.

Fig. 7. Part of the germinal vesicle (GV) of an oocyte from a follicle $0.5-0.7 \mathrm{~mm}$ in diameter cultured for $48 \mathrm{~h}$. Condensed chromatin (ch) is close to the convoluted nuclear envelope (arrows); large Golgi structures (G) are proximal to the GV. L, lipid droplets. $\times 25000$. 


\section{Culture for $48 \mathrm{~h}$}

After $48 \mathrm{~h}$ of culture (Table 1), $41 \%$ of Class A oocytes still remained at the germinal vesicle stage, whereas $35 \%$ had progressed to prometaphase and only $4 \%$ to metaphase I. In Class B, $23 \%$ of the oocytes had progressed to metaphase I, while $17 \cdot 3 \%$ reached metaphase II. The percentage of oocytes that completed the first meiotic division increased significantly in Class $\mathrm{C}$ in which about $50 \%$ of the oocytes extruded the first polar body and $31 \%$ remained in metaphase $\mathrm{I}$. About $76 \%$ of Class D oocytes completed nuclear maturation in vitro.

The percentage of degenerative oocytes with clumps of condensed chromatin was nearly the same (about $20 \%$ ) in follicular Classes A, B and C.

The different stages of nuclear progression were analysed by electron microscopy. In 3 oocytes out of 6 from Class A, 3 out of 4 from Class B and 1 out of 4 from Class C arrested at the germinal vesicle stage after $48 \mathrm{~h}$ of culture, 2 or 3 small nucleoli were found instead of a single large nucleolus (P1. 2, Fig. 6); these totally compact and agranular nucleoli were frequently adjacent to the nuclear envelope. Fragmentation of the nucleolus was probably due to a degenerative process. The germinal vesicle of these oocytes was round and more or less centrally located in the cytoplasm. In oocytes in which nuclear maturation was starting, the germinal vesicle was peripherally located and the nuclear envelope was markedly undulated; the chromatin was condensing close to the nuclear envelope and some large areas of Golgi were present in the cytoplasm close to the germinal vesicle (Pl. 2, Fig. 7). When metaphase I and II spindles were present (in 1, 3 and 2 oocytes from Classes A, $\mathrm{B}$ and $\mathrm{C}$ respectively) their organization according to chromosome distribution, kinetochores and microtubule arrangement (Pl. 3, Figs 8 \& 9) was like that of oocytes from large antral follicles matured in vitro (unpublished data). Furthermore the cortex of these oocytes in metaphase I or II was almost empty of cytoplasmic organelles such as mitochondria, endoplasmic reticulum, Golgi and lipid droplets, but the cortical granules had migrated towards the oocyte periphery and were aligned along the plasma membrane as in preovulatory oocytes matured in vitro.

\section{Discussion}

The acquisition of meiotic competence in oocytes has often been correlated in the literature with the appearance of an antral cavity and oocyte size. It has been demonstrated for several rodent species that oocytes become competent to resume meiosis in vitro when the follicles enclosing them develop an antrum (Erickson \& Sorensen, 1974; Iwamatsu \& Yanagimachi, 1975; Bar-Ami \& Tsafriri, 1981). However, the present study indicates that pig oocytes do not acquire this competence to resume meiotic maturation when the antrum is formed. In the pig, the antrum is fully differentiated in follicles $0.4-0.8 \mathrm{~mm}$ in diameter (Crozet et al., 1981) but only $12 \%$ of the oocytes liberated from these follicles resume meiosis after $24 \mathrm{~h}$. Successful germinal vesicle breakdown occurred in oocytes from follicles $>1 \mathrm{~mm}$ in diameter. Conflicting results have been reported concerning the ability of oocytes from follicles $1-2 \mathrm{~mm}$ in diameter to progress beyond the germinal vesicle stage (McGaughey et al., 1979; Tsafriri \& Channing, 1975; Anderson \& Hillensjö, 1982). The present work, using serial follicular size classes, partly elucidates these conflicting results because 28 and $6 \%$ of the oocytes from follicles $0.8-1.6 \mathrm{~mm}$ and $1.7-2.2 \mathrm{~mm}$ in diameter, respectively, remained in the germinal vesicle stage after $24 \mathrm{~h}$ of culture. A substantial difference in maturation rate (oocytes in metaphase II) was also noted in these follicular classes after $48 \mathrm{~h}$ of culture.

The majority of pig oocytes in follicles $>1 \mathrm{~mm}$ in diameter acquired the competence to resume meiotic maturation in vitro but only those of follicles of about $2 \mathrm{~mm}$ in diameter completed the first meiotic division in vitro. These results confirm the previous findings of Tsafriri \& Channing (1975) for pigs and of Sorensen \& Wassarman (1976) for mice who concluded that the ability to undergo germinal vesicle breakdown and continue to metaphase I was acquired earlier during folliculogenesis than the ability to reach metaphase II. 
The increase in the size of pig oocytes from 100 to $120 \mu \mathrm{m}$ in small antral follicles appears to be related to their ability to resume meiosis in vitro. While oocytes with a mean diameter of about 100 $\mu \mathrm{m}$ cannot complete germinal vesicle breakdown, those with a mean diameter of $115 \mu \mathrm{m}$, which is nearly equal to that of full-sized pig oocytes (McGaughey et al., 1979), seem to be able to complete meiotic maturation. In the same manner, hamster and mouse oocytes successfully mature in vitro only when they have reached full size (Iwamatsu \& Yanagimachi, 1975; Sorensen \& Wassarman, 1976).

When the antrum is forming in pig follicles $0.5 \mathrm{~mm}$ in diameter, the oocytes have a fibrillogranular and vacuolated nucleolus and are intensively engaged in RNA synthesis (Crozet et al., 1981). The present data indicate that, at this stage, their ability to resume nuclear maturation in vitro is very limited and none complete it. During further follicular development, the nucleolus is progressively compacted and oocyte rRNA synthesis significantly decreases (Crozet et al., 1981). After $24 \mathrm{~h}$ of culture, a large number of these oocytes $(66 \%)$ complete germinal vesicle breakdown; only $17 \cdot 3 \%$ of them reach metaphase II after $48 \mathrm{~h}$ of culture. In Class C follicles (diam. 1.7-2.2 mm), the process of nucleolar compaction is completed in the majority of oocytes and a relatively high percentage $(50 \%)$ of them progresses to metaphase II after $48 \mathrm{~h}$ of culture. This percentage increases to $76 \%$ in Class $\mathrm{D}$ follicles (diam. $3-5 \mathrm{~mm}$ ). It is tempting to postulate that the morphological and functional changes that occur in oocytes from early antral follicles constitute one of the stages required for oocyte acquisition of meiotic competence.

The high rate of rRNA and hnRNA synthesis which characterizes pig oocytes from early antral follicles (Crozet et al., 1981) is probably needed for the storage of some information necessary to the initiation and completion of the first meiotic division. Golbus \& Stein (1976) proposed that the changes that take place in the pattern of protein synthesis during mouse oocyte meiosis are controlled by messenger RNAs that are already present and not by RNA synthesized during meiosis. It is possible that inability to resume meiotic maturation is due to the absence or insufficiency of messenger RNAs coding for a cytoplasmic factor, e.g. like the maturationpromoting factor in amphibians (Masui \& Markert, 1971). The present experiments demonstrate that the majority of pig oocytes from follicles $>1 \mathrm{~mm}$ in diameter can progress beyond germinal vesicle breakdown and that they probably already possess the aptitude to synthesize these cytoplasmic factors.

A significant decrease in rDNA transcriptional activity occurs during the process of nucleolar compaction at the time when the oocytes reach full size, although an active hnRNA synthesis seems to be maintained (Crozet et al., 1981). Some RNA synthesis activity has been demonstrated up to resumption of meiosis in mouse oocytes from antral follicles (Rodman \& Bachvarova, 1976; Wassarman \& Letourneau, 1976). This late RNA synthesis in oocytes may also play a role in the final acquisition of their meiotic competence, as shown by the fact that oocyte ability to mature in vitro continues to increase in larger follicles (Tsafriri \& Channing, 1975; present results).

We thank Professor C. Thibault for critical reading of the paper; Mrs C. Brachet and M. V. Pech for skilful technical assistance; Mrs Solari for statistical analysis; Mrs Daifuku for the English translation of the text; Miss Du Créhu for typing; and M. Slagmulder for the photographs.

\section{References}

Anderson, L.D. \& Hillensjö, T. (1982) Lack of effect of a gonadotropin-releasing hormone agonist upon meiosis in isolated porcine oocytes. Acta physiol. scand. 114, 623-625.

Bar-Ami, S. \& Tsafriri, A. (1981) Acquisition of meiotic competence in the rat: role of gonadotropin and estrogen. Gamete Res. 4, 463-472.
Crozet, N., Motlik, J. \& Szöllösi, D. (1981) Nucleolar fine structure and RNA synthesis in porcine oocytes during the early stages of antrum formation. Biol. Cell 41, 35-42.

Erickson, G.F. \& Sorensen, R.A. (1974) In vitro maturation of mouse oocytes from late, middle and preantral graafian follicles. J. exp. Zool. 190, 123-127. 
Golbus, M.S. \& Stein, M.P. (1976) Qualitative patterns of protein synthesis in the mouse oocyte. J. exp. Zool. $198,337-342$.

Iwamatsu, T. \& Yanagimachi, R. (1975) Maturation in vitro of ovarian oocytes of prepubertal and adult hamsters. J. Reprod. Fert. 45, 83-90.

Masui, Y. \& Markert, C. (1971) Cytoplasmic control of nuclear behaviour during meiotic maturation of frog oocytes. J. exp. Zool. 177, 129-146.

McGaughey, R.W., Montgomery, D.H. \& Richter, J.D. (1979) Germinal vesicle configurations and patterns of polypeptide synthesis of porcine oocytes from antral follicles of different size, as related to their competency for spontaneous maturation. $J$. exp. Zool. 209, 239-254.
Rodman, T.C. \& Bachvarova, R. (1976) RNA synthesis in preovulatory mouse oocytes. J. Cell Biol. 70, 251-257.

Sorensen, R.A. \& Wassarman, P.M. (1976) Relationship between growth and meiotic maturation of the mouse oocyte. Devl Biol. 50, 531-536.

Tsafriri, A. \& Channing, C.P. (1975) Influence of follicular maturation and culture conditions on the meiosis of pig oocytes in vitro. J. Reprod. Fert. 43, $149-152$.

Wassarman, P.M. \& Letourneau, G.E. (1976) RNA synthesis in full-grown mouse oocytes. Nature, Lond. 261, 73-74.

Received 27 December 1983 